\title{
Joys and challenges of motherhood for Australian young women of preterm and full- term infants: an Interpretative Phenomenological Analysis
}

\section{Nicola Sheeran}

Nicola Sheeran, School of Applied Psychology, Mt Gravatt Campus, Griffith University, Mezzine ridge Road, Mt Gravatt, 4111, Brisbane, Australia.

Ph:61 737354431 Email: N.sheeran@griffith.edu.au

\section{Liz Jones}

School of Applied Psychology, Mt Gravatt Campus, Griffith University, Brisbane, Australia Mezzine ridge Road, Mt Gravatt, 4111, Brisbane, Australia.

Ph: 61737353365 Email: L.Jones@griffith.edu.au

\section{\& Jen Rowe}

School of Nursing and Midwifery, University of the Sunshine Coast, Australia 90 Sippy Downs Dr, Sippy Downs QLD 4556

Ph: 61754565160 Email: jrowe1@usc.edu.au

\section{Corresponding Author}

Nicola Sheeran, School of Applied Psychology, Mt Gravatt Campus, Griffith University, Mezzine ridge Road, Mt Gravatt, 4111, Brisbane, Australia.

Ph: 61737354431 Email: N.sheeran@griffith.edu.au

\section{Acknowledgements}

We also acknowledge the support for this project provided by Ms Anita Hosking and Ms Lisa Farnell.

\section{Funding}

This work was supported by Department of Communities, priority research funding, Queensland Government (grant H:ISP\SEB\Research_com\81). 
The joys and challenges of motherhood

\begin{abstract}
Objective: This study aimed to further our understanding of the daily experience of being a young mother for Australian young women who have preterm infants.

Background: Both preterm birth and adolescent childbearing are associated with increased risk of poor maternal and infant health outcomes. However, little research has explored how having a preterm infant influences the experience of being a mother for young women or whether it differs from having a full-term infant.
\end{abstract}

Methods This Interpretative Phenomenological Analysis study analysed interviews with 14 young women (15-19yrs; 10 preterm \& 4 full-term) who were interviewed three times over the first 12 months of parenting.

Results: Preterm birth did not detract from the joys associated with becoming a mother, which was central to all mother’s stories. Instead, preterm birth exacerbated challenges faced by all young women, such as transportation difficulties and negative judgment from others. Unique challenges included lack of embodied interaction with their infants and navigating the hospital system. Young women frame the experience of being a mother in terms of immediacy and daily demands.

Conclusion: This research further challenges the view that early motherhood is detrimental to young women, by demonstrating how the polemics of enjoyment and challenge co-exist in the experience of mothering on a day-to-day basis. Using global categories such as age or birth status to assess risk may not be appropriate as they do not provide nuanced criteria for establishing which mothers need assistance.

\title{
Keywords
}

adolescents, interpretative phenomenological analysis (IPA), motherhood, parenting, preterm 
The joys and challenges of motherhood

\section{Background}

Very little research has examined how adolescent women experience motherhood following a preterm birth, nor whether adolescent mothers of preterm infants experience additional challenges compared to those who give birth to a full-term infant. Parenting as a young woman is a complicated issue that has received sustained attention from researchers and policymakers over the past few decades (Furstenberg, 1991; Graham \& McDermott, 2006; Linders \& Bogard, 2014; Montessoro \& Blixen, 1996; Rai, Singh, Kumar, \& Parasuraman, 2013). A large body of literature has amassed suggesting that young mothers are a heterogenous group, whose ability to parent effectively is influenced by a number of factors that interact in complex ways (Abrahamse, Morrison, \& Waite, 1988; Ruedinger \& Cox, 2012; Schellenbach, Whitman, \& Borowski, 1992). While the extent of the difficulties and challenges young mothers face is still being debated in the literature, it appears there are a number of important factors contributing to positive maternal adjustment, including external resources (such as social support), internal resources (such as cognitive readiness, age, learning ability, psychosocial adjustment, self-care, realistic 'core' expectations and beliefs about parenting), and system level factors (such as socioeconomic status, access to housing, low situational stress) (Hunt-Morse, 2002; Kleiber \& Dimidjian, 2014; Knaak, 2008; Schellenbach et al., 1992; SmithBattle, 2012). Deficits in these areas are associated with less positive outcomes for mothers and infants (Letourneau, Stewart, \& Barnfather, 2004). How a preterm birth interacts with the complex lives of young mothers is, however, unclear (Sheeran, Jones, Rowe, \& Zimmer-Gembeck, 2013).

Research has suggested that being born to a young mother and being born preterm or low birth weight (LBW) are separate risk factors for adverse maternal and infant outcomes (Furstenberg, Brooks-Gunn, \& Chase-Lansdale, 1989) and combined represent a double risk for poor outcomes (Thurman \& Gonsalves, 1993). However, little empirical research has 
The joys and challenges of motherhood

investigated this proposition, with most research on preterm birth undertaken with adult mothers. The adult literature suggests that the birth of a preterm infant is associated with a range of acute and chronic stressors both while the infant is in hospital, and as mother and infant transition home (Davis, Edwards, \& Mohay, 2003; Davis, Edwards, Mohay, \& Wollin, 2003). Postnatal depression can be a relatively common experience for adult mothers who deliver preterm (Miles, Holditch-Davis, Schwartz, \& Scher, 2007), with younger maternal age associated with greater levels of distress (Meyer et al., 1995).

One limitation is that previous research has primarily been conducted with adult mothers, most of whom were educated, in stable relationships, and employed. These factors have been found to assist in positive maternal adaptation to the situation (Cronin, Shapiro, Casiro, \& Cheang, 1995; Davis, Edwards, Mohay, et al., 2003). The few studies that recruited younger mothers collapsed over age, making it difficult to know if there are aged based differences in the experience (Cleveland, 2008). As such, the question remains as to how young ‘teen' aged mothers experience the transition to motherhood with a preterm infant. Until recently, the limited literature that had focused on teenage mothers of preterm infants had been concerned with infant outcomes (Field, Widmayer, Stringer, \& Ignatoff, 1980) and not the psychological health or maternal adjustment of the adolescent mother. Field et al's (1980) study suggested no differences between adult or teenage mothers of fullterm or preterm infants in reported anxiety. More recently, research found that young women were reporting less distress than adult mothers of preterm infants (Farnell, Jones, Rowe, \& Sheeran, 2012; Sheeran, Jones, \& Rowe, 2013). Compared to adult mothers, young mothers were also less likely to report that the experience was against expectations (Sheeran, Jones, \& Rowe, 2013).

The aim of the current research was to further our understanding of the daily experience of being a young mother for Australian young women who have preterm infants. 
The joys and challenges of motherhood

Of particular interest was understanding whether infant birth status provided a meaningful way of conceptualising the heterogeneity of adolescent mothers' experiences. Interpretative Phenomenological Analysis (IPA) (Smith, Flowers, \& Larkin, 2009) was selected to explore the lived experience of young Australian women who gave birth to preterm or full-term infants over the first 12 months of parenting.

\section{Method}

\section{Design}

\section{Setting and participants}

Qualitative data were collected during 3 interviews over the first 12-months of motherhood with 14 English speaking primiparous women aged 15-19 years, who had given birth to either a preterm ( $<37$ weeks completed gestation; PT; $N=10$ ) infant who was in the special care nursery (SCN) or a full-term infant ( $\geq 37$ weeks; FT; N=4).

Participants with ongoing maternal health issues or child alert notifications regarding cognitive or intellectual impairment were not eligible. Table 1 provides participant characteristics for each of the mothers. Pseudonyms have been used to protect the identities of the women involved. The young mothers were recruited from 4 hospitals (both regional and metropolitan) in South-East Queensland, Australia as part of a larger study (Jones, Rowe, \& Sheeran, 2010), which used a total sampling strategy. Mothers in the current study were the only women to provide all data.

\section{Design and procedure}

This research project was approved by the relevant institutional and hospital research ethics committees. The young women provided informed consent to participate without the need for parental consent.

A qualitative longitudinal design was used to examine influences on the daily experience of being a mother, and how these influences shaped the meaning and challenges of 
The joys and challenges of motherhood

mothering for the participants. IPA is an inductive, data-driven theme-building approach that later integrates findings within existing theoretical models (Smith, 2011). IPA is idiographic , in that the concern is with what the experience is like for this person, elucidating what sense this particular person is making of what happened to them (Smith et al., 2009).

Individual guided interviews were conducted 1 week prior to discharge from the SCN (PT) or within 2 days post birth to 1-week post discharge (FT), 3-4 months post discharge, and 12 months post discharge. Consistent with IPA (Smith, 1995; Smith et al., 2009), participants led the discussion, while the interviewer guided the process based on the interview schedule and prompts. The following areas were explored in each interview:

- Background demographic details

- Infant progress/development

- Experiences of pregnancy/parenting

- Coping/support

- Impact of parenthood on life

- Expectations of parenting

- Perceived impact of prematurity

Interviews were digitally recorded then transcribed verbatim and ran from 45 minutes to 1.5 hours in length. Interviews were conducted either at the hospital or in the participant's house by the first author. Demographic data is presented in table 1 .

Data analysis Data were analysed using the steps outlined in the IPA process (Smith, 2011; Smith \& Osborn, 2008). The aim of this analysis was to report core themes supported by excerpts and accompanied by descriptive and interpretative commentary. Each interview was analysed separately, with descriptive comments and emergent themes noted before looking across interviews for interconnections, convergence, and divergence in themes across participants. All time 1 interviews were analysed and aggregated before time 2 interviews were analysed and aggregated, followed by Time 3 interviews. Interconnections across time were then identified and final themes were developed, synthesizing the material across time and participant. Cross checking was undertaken by the research team to explore how earlier 
The joys and challenges of motherhood

analyses across time and within participants were represented by the central organizing themes, ensuring that a Gestalt had been reached. Detailed information about the coding and interpretative processes (including reflexivity and rigour) are outlined in Sheeran (2012). Reflexive note: Consistent with the hermeneutic tradition in Interpretative Phenomenological Analysis (IPA) (Smith et al., 2009), it is important to consider what I, as first author and principal investigator, brought to the research project. Coming into this project I had a background in community services, working with adolescents to reduce risk of unplanned pregnancy, sexually transmitted infections and high risk behaviours. I also had a theoretical background in stress and coping and psychopathology, which informed my initial assumptions that adolescent mothers would be struggling as they transitioned to motherhood. Over time, as I interacted with the young mothers, I challenged my own assumptions, allowing me to acknowledge positive aspects of their experiences.

\section{Findings}

One superordinate theme emerged that best answered the research question for this project: The dual nature of motherhood. This superordinate theme describes the way young mothers navigated everyday parenting experiences of delight and unexpected enjoyment and challenges and complexities. Despite the researchers' focus on the experience of having a preterm birth, the findings highlighted many common experiences as the young women navigated parenting, regardless of whether their infant was born preterm or full-term. The theme was common to all young mothers (FT and PT), however there were experiences that were unique to the mothers of preterm infants. The sub themes are detailed below and include excerpts from the participants' narratives to exemplify the themes, including convergent or divergent experiences. All excerpts are verbatim, except where changes were made to increase clarity and readability or to ensure anonymity. 
The joys and challenges of motherhood

\section{The dual nature of motherhood}

The dual nature of motherhood reflects the tensions created by the competing aspects of parenting, and emerged as the core aspect of the experience of being a mother for all young women in the research. Being a mother was enjoyable and the young women appeared to rejoice as their infants grew and developed. The delight the mothers felt about their infants was a dominant theme evident in all interviews and across time. Enjoying parenting reinforced the young women's belief in the rightness of parenting at a young age, and mothering as a deliberate experience rather than mistaken or accidental. At the same time mothers talked about the challenges and how these changed over time, suggesting the experience was multifaceted and sometimes contradictory. How the contradictory experiences coexisted will be explored first followed by other challenges not related to the joy of parenting.

Mothers talked about the love they felt for their infants and how it made them feel about themselves. Most young women made simple expressions of how becoming a mother was “good” but also unexpectedly so.

“Its just totally different like it’s good being a mum now really good really happy. But beforehand I just didn't know if I was going to be happy or not...Yeah I am really happy now” (Juliana T1 PT).

The young women had anticipated parenting would be a more negative experience based on what they heard, from people they knew or more generally. Feeling positive was unexpected.

"It's not to worry about. It's a good experience. It's a blessing to have a baby really it is... You get stressed. Everyone tells you there is so many things to worry about, your whole live will disappear and yatta, yatta, yatta. No it’s excellent” (Lily T2 PT)

Having an infant was described as something that enhanced their lives. There was no one aspect of being a mother that stood out. Instead, the mothers just enjoyed their infants.

“I love it [Laugh], I love it, I absolutely love it, I enjoy it, I'm really enjoying him.” (Skye T2 FT) 
The joys and challenges of motherhood

Over time, the mothers' narratives shifted and the expressions of love and joy were more closely tied to what their infant did. As such, their enjoyment was expressed in everyday activities such as playing, feeding, changing, bathing and noting how their sleep routines had evolved over the months. Their infant's growth and developing abilities were a source of enjoyment, as Lily’s narrative illustrates.

"The last couple of days she actually got the muscles to push her belly up off the ground. So I guess her crawling is less than a month away I'm thinking. I was so proud of her when I seen her do that.” (Lily T2 PT) T3

Delight and enjoyment often coexisted with struggles and challenges.

"Oh just watching her grow and...Starting moving and holding her neck up and stuff. Which has been good. Struggled sometimes but that happens... I love interacting with her and like now she starts to interact back, like smile and laugh and sit up.” (Jenna T2 PT)

Their infants' changing behaviours were challenging to their parenting. Some women described their difficulty understanding and managing, and that they were tested.

“... some mornings he'll wake up talking to me and that and some mornings he'll wake up [screams]... and that's when he's just crying for no reason is when it's aaahhhh.” (Tenielle T2 FT).

The constancy of the early demands became overwhelming for many (but not all), and the need for support and reassurance was high.

"Yeah, it's been okay but I try and convince myself that I can do it, but I've had moments where I get really, really frustrated and then I cry” (Emily T2 PT).

And while Emily and Tenielle were single parents, possibly explaining some of their feelings of being challenged, even mothers in committed relationships found the reality of early parenting more challenging than they had expected. These challenges included the constancy of parenting based on the infant's dependency and needs, the lack of sleep, and difficulty in getting day-to-day things done.

"It's more demanding than I realised. Well it's not so much now but in the beginning you don't realise when you're going through it and you look back to now, to what I 
The joys and challenges of motherhood

have to do now to what I had to do then, you don't realise how demanding it really was.” (Claire T2 FT).

For most mothers things became easier over time as routines solidified, they slept more and they felt their babies were more settled. This provided the young women with a growing sense that they could do this; they could be 'good enough' parents. Handling the responsibility of parenting was something the mothers took pride in.

"Yeah, and you look at your responsibilities and once you take care of your responsibilities you can be proud of yourself, and I'm proud of how Lakeisha is.” (Emily T3 PT)

The challenges continued throughout the first year. Most mothers reported that managing their own frustration at their infant’s behavior was a significant challenge. They described needing to constantly monitor their infants, who were becoming mobile and exploring their environment. Some mothers ascribed meaning to the behaviours, such as “cheekiness” and "naughtiness”, and struggled to find appropriate ways to interact with and guide their 1 year olds. Lisa, for example, had a disciplinary model in mind as she responded to behaviours she perceived as difficult.

“Frustrating if anything it’s frustrating. Especially with him, he doesn't listen. It's all no and he tells you no back. You can’t smack him because he laughs and says, "Mack” and hits you anyway" (Lisa T3 PT).

Many mothers described their frustration at their infants. Those who identified their infant's behaviour as appropriate for age, rather than because the child was difficult or naughty, were less frustrated. Similarly, mothers who adapted their lives to be responsive and accommodating to the infant reported more ease and enjoyment with the parenting experience and less challenge. Some mothers, particularly those who had been employed or who had developed skills in other contexts (i.e. Claire and Juliana), appeared better prepared and able to adapt, while others learnt this over time through parenting. The process of adapting over time is exemplified by Renee. Renee initially spoke of how things would be easier when her infant or circumstances changed (i.e. being at a different hospital or home from hospital, 
The joys and challenges of motherhood

infant being independent, infant being older). She blamed her infant when things were not easy, with her frustration evident.

"If he didn't drink a bottle I'd get the shits it took me so long to get the milk and everything. I blamed him for everything pretty much.” (Renee T3 PT).

Things became easier when Renee herself adapted and became responsive to the needs of the infant.

"Preparation is definitely the key to being a good mother. I like to wake up earlier than him now and have everything ready, so when he wakes up he can be fed straight away... So if you have a nappy there ready and have everything in the shower ready, you've got to get yourself into a routine. ” (Renee T3 PT).

Renee identified several key internal resources that she developed over time such as being prepared and organized. The paradoxical effect of prioritizing the infant's needs was that it made things easier for the mother.

The young women noted that it was less acceptable to discuss the challenges of parenting. The paradoxical experience of being a mother and a young woman is evident in Jenna's words. Again it is clear that the love for the infant is central, although being a parent could be challenging and restrictive at her age.

NS: $\quad$ So are you enjoying motherhood at the moment...?

Jenna T3 FT: Can I say, “No” [laughs]...That’s terrible...I love it, I wouldn’t change it, yeah... it's just but there's loads of things... being 19... And it's just all of my friends are 19 and are going out...I love motherhood, I love Melissa... I would have loved to have Melissa in 5 years from now. I love it.

The restrictions parenting created was one of the main challenges mothers reported.

However, this was seen as a short term challenge and one the ensuing joy associated with having a child made worthwhile.

“you can’t do what you want to do, like you can't do everything that you used to do. I mean I can't just go down town now when I feel like it ... but now I don't mind staying home. It's still good I can live without going out... Having someone around like is not so boring” (Danielle T1 FT) 
The joys and challenges of motherhood

'Motherhood' and 'parenting' were terms evident in the narratives when the young women explained their experiences of parenting. This highlights that they perceived the positives and challenges as part of the universal experience of being a mother rather than because they were 'teenage mothers'.

Practical difficulties with housing, transport, and financial strain significantly impacted on the daily experience of parenting for some young mothers. Importantly, not all mothers experienced these challenges, with some in strong economic positions (i.e., owning their own homes/cars).

Stable housing was a significant issue for several mothers, who were unable to find affordable and suitable accommodation, unable to legally sign leases and were often reliant on friends and new acquaintances to provide accommodation.

"I have friends in [suburb], and I was meant to live with them for a while...I stayed there for a couple of nights and the real estate rang them up and complained about Bailey's crying from the old lady next door... So they said he has to get out... It's just been mayhem”. (Tenielle T2 PT).

Lack of stable housing meant the mothers were unable to set up a nursery or create a space for themselves. Toys, clothes, and supplies were often left in several locations or left packed in boxes, making day-to-day care of the infant difficult. Most women reported stability in housing by 12 months. Most were living with their partners in rental properties, affording them more space and freedom but also a reduction in support from family and decreased time out from the infant. In addition, living alone was often associated with an increase in financial strain and concerns about finding appropriate flatmates.

Half of the mothers experienced financial strain. Most were reliant on government payments, and for two mothers payments were delayed for months while paperwork was processed. These young mothers were then reliant on family members to provide financial support. The mothers struggled at times to provide the basics for their infants, and were not able to indulge their infants as they felt they should. 
The joys and challenges of motherhood

"We're left with nothing, no money or anything for fuel after shopping's done, the rent's paid I've nothing... The worst thing is that Christmas is coming and I can't afford it” (Skye 2 PT).

Negotiating acceptable support from family, partners and friends was a struggle, as the young women sought to balance their need for support with their need for autonomy in the parenting role. Negotiating the 'right' kind of support from parents was difficult for many, as the young women reported receiving unwanted advice instead of help with little things or time out.

"You kind of really needed help but you didn't know how to ask them... You don't want them to come in and parent fully, which our mums are likely to do [laughs], just because they love us.” (Bronte T3 PT).

Bronte continued

“...being a young parent, if you look like you're doing okay, then they'll leave you alone, which is good. But if you ask for help from them, they think it's because of your youngness that you need the help. So then they take over and you don't really want them to take over, you just really want them to just help.” (Bronte T3 PT).

Support was perceived negatively when a parent or a professional lectured them, took over, challenged them, or interfered. Alternatively, support was perceived positively when it honoured the young woman's autonomy in the parenting role, by providing guidance and advice, as and when requested. This need for autonomy was also seen in the young mothers' accounts of finding 'my way' of parenting; a way of parenting that suited the mother and baby's temperament and needs.

The challenges of a preterm infant. Differences in the narratives of the young women who had preterm and full-term infants were only evident early in the parenting experience, where young mothers of preterm infants reported challenges prior to taking their infants home. The first challenge was negotiating the hospital system, including negotiating the care of their infants with staff who they perceived as not supporting their attempts to be autonomous parents, and restrictions in the care they could provide to the infant. 
The joys and challenges of motherhood

“... and like some of their ways of doing things kind of... were not really my way...she just basically did it all so how was I supposed to learn...but I want to have a turn myself”. (Jade T1 PT).

Compounding their struggle was the change of nurses each shift, as with changing staff came new rules about the nursery and care for the infant. The young women perceived high levels of negative judgment from hospital staff and felt they were treated differently in the nursery due to their age.

"I was a young Mum and some of the looks I'd get... I think there is a big difference because I had three older ladies in the room... and they got treated with a lot of respect, more respect than what I did; I picked up on that straight away so. Just disappointing because ... doesn't matter how old you are, every Mum should get treated the same way.” (Skye T2 PT).

This continued as the young mothers sought support from health professionals in the community.

“... I was trying to tell [the paediatrician] that we couldn’t figure out whether there is anything actually wrong with him or not. But he looked at me and said, "Are you telling me that by now you still don't know what your baby's screams are?" He was doing it in a mocking way, and I actually started bawling my eyes... 'cause I was like, "I don't need judgement. I need your help! I don’t need you to criticise my parenting.” (Bronte T3 PT)”

Young women developed strategies for mothering in the complex nursery

environment. Some created a sense of predictability and control through indicators of progress in their infants, and using social comparison to assess progress and normality. Other young women defined their roles and the roles of the nurses into parenting (i.e., feeding, bathing, changing) versus medical care in order to have distinct responsibilities in the cocaring relationship.

"I basically do everything for her while she is here... they do her temperature and stuff like that when they need” (Juliana T1 PT).

The young women also adopted an idealisation strategy, whereby home became the place where they would become mothers. In part, the young women ignored what was 
The joys and challenges of motherhood

happening and their discomfort in the nursery because they believed everything would be fine once they were home.

“...It will be so much better when he’s home... just feeling like being a family instead of sort of having to run back and forwards to the hospital and it's hard to get to sleep at night because I don't know what he's doing...I think it will be easier with no driving. I'll be able to just sit down and sleep when he is asleep and just relax" (Renee T1 PT).

Preterm birth also exacerbated the practical difficulties experienced generally by the young women. Transport to and from the hospital was difficult to arrange and sustain with most were reliant on friends and family members, as they did not have licences or cars, and had limited access to public transport, and long travel times. Transport difficulties impacted the mothers' attempts to parent as they would often miss feeding times and could not devote as much time to their infants, which further impacted the bonding process.

"It's just frustration, because they'd already started to tube feed when I got there, and I was only 5 minutes late. I'm like, you could have waited or you could have called me” (Laura T1 PT).

Young women who had preterm infants also found the emotional side of the experience challenging, an "emotional rollercoaster”. All mothers of preterm infants described the challenge of separation from their infants. Young mothers missed seeing and holding their infants and keenly felt the separation in the maternity ward and following their own discharge.

“it was just a lost feeling, like something was missing...I just spent 9 months carrying her and pushing her around and now I don't even have her near me. It was like they'd almost taken her away from me” (Lily T1 PT).

To cope with the lack of embodied interaction with their infants the women invoked an image of the 'absent baby' by interacting with photos of their infants, allowing the process of bonding and attachment between mother and infant to continue in the absence of the physical presence of the baby.

"I've been trying to get into the routine without her being there. I try and we'll get the photos out and we go to her bedroom and her little bassinet” (Holly T1 PT). 
The joys and challenges of motherhood

When touch was not available, other senses such as sight were used and bonding by watching occurred. Despite the challenges the young women's narratives suggested that the experience of being a mother and the positives associated with this outweighed the challenges.

"Ohh well I didn’t expect to have a preterm baby but it's been alright... Yeah it has pretty well its been a little bit hard - the hardest time is leaving the hospital and leaving her here but other than that it has been pretty good” (Juliana T1 PT).

Of particular note was the lack of anxiety about taking their infants home or of potential future health issues, both notably absent from their narratives.

\section{Discussion}

The current project aimed to further our understanding of the experience of being a young mother of a preterm infant. By exploring the narratives of adolescent mothers of preterm and full-term infants, the current study also investigated whether these two groups of mothers belong in the same space conceptually and practically in terms of service provision, and whether there are additional challenges and needs due to the preterm birth of an infant. Our findings suggest very few differences in the way the young women narrated or framed their experience.

The young women in this study took pleasure in the unexpected enjoyment they experienced when mothering their infants. It was also in each moment that they responded to a variety of challenges, including managing the constancy of demands, changing characteristics of the infant, practical difficulties (i.e. housing and transport) and negotiating acceptable support. Despite concerns about poor outcomes for young mothers at academic, policy and service provision levels (Furstenberg, 1991), the current findings suggest that the young women themselves were not concerned for themselves or their infants, with an absence of concerns about either psychological and developmental delays in their narrative about the first 12-months of parenthood. Instead, their experience was framed by the daily demands of how to manage their infant and parent effectively. The meaning and experience of mothering 
The joys and challenges of motherhood

was also framed by the level of stability in their daily life, particularly in terms of housing, income, and appropriate support. This suggests that their frame of experience was immediate and daily. The current findings suggest that those helping adolescent mothers should focus on resolving these daily challenges to reduce risk, develop skill, and facilitate parenting.

Research with adult mothers suggests that the degree to which the mother enjoys the daily tasks of parenting depends on the match between their expectations and actual experience of parenting (Belsky, 1985; Delmore-Ko, Pancer, Hunsberger, \& Pratt, 2000). The narratives of the mothers in the current research suggest that they received many messages about how hard the experience would be for them as young mothers, setting up an expectation of difficulty and not coping. These messages lowered expectations, with the reality of parenting then less negative than expected, which may explain why enjoyment is so prominent in the narratives of young mothers, and their surprise that parenting was so enjoyable. Fostering the joy in being a mother experienced by young women is more likely to keep them engaged in the process of mothering.

Despite a posited double risk of poor maternal outcomes for young mothers of preterm infants (Thurman \& Gonsalves, 1993), the current research found that preterm birth was not a salient part of the experience of mothering. Managing a preterm birth was not particularly distressing, just one of several challenges. This suggests that the level of risk for young mothers of preterm infants may be overstated - at least for the mother, if not for the infant. The current findings suggest that the positive perceptions that mothers hold of parenting are protective in the nursery context. Specifically, the young mothers were not assessing risk in the same ways reported by adult mothers of preterm infants, with a lack of concern expressed about the long term difficulties that could be associated with preterm birth. The current study supports the proposition that young mothers of preterm infants are more present focussed and more focussed on the daily experience of parenting, while previous 
The joys and challenges of motherhood

literature suggests adult mothers are more future focussed and experience anticipatory anxiety (Farnell et al., 2012; Sheeran, Jones, \& Rowe, 2013). This is likely due to that fact that young women are generally less differentiated and complex in the appraisals they make about situations (Rowley, Roesch, Jurica, \& Vaughn, 2005) and are still developing the cognitive skills needed to accurately evaluate potential consequences (Crone, 2009;

Fischhoff, 2008). In this context, the young women's frame of reference may be a protective factor for their psychological functioning. The current findings also suggest that we cannot use group level categorisations meaningfully to determine risk or to provide services - it is not about young or older or about preterm versus full-term. Instead, consideration of the degree of pre-existing knowledge, skill and ability should be included in any assessment process, along with assessment of the infant's health status. On the other hand, some mothers had multiple practical challenges that influenced their ability to parent and the challenges, for example accommodation, poverty, lack of access to transport, are not factors these mothers had the agency to change. These findings add to the growing body of literature suggesting that improved provision of basic needs, including stability in housing and support, would increase outcomes for both young mothers and children (Jones et al., 2010; Romagnoli \& Wall, 2012; Ruedinger \& Cox, 2012; SmithBattle, 2012). One implication for practice is that the assessment process should be viewed as one of evaluating the mother's internal and external resources and interventions focused on developing these resources. This would also reduce the young mother’s perceptions and feelings of being stratified by age.

One notable limitation is the generalizability of the current findings to all adolescent mothers. As well as exploring the experience from only a small number of young women, the majority of the young women in this study were in stable relationships with their partners. This is at odds with other Australian research that found up to $47 \%$ of fathers were not involved with the mother or infant (Quinlivan, Petersen, \& Gurrin, 1999). While the 
The joys and challenges of motherhood

Quinlivan study did appear to have very high rates of uninvolved fathers compared to rates for the UK and USA (Bunting \& McAuley, 2004), it highlights that the current sample may be overly representative of partnered young women. Future research should explore the experiences of these two groups of young women in more depth.

The current study also included mothers whose infants differed on gestational age at birth, length of hospitalisation, birth weight, and degree of difficulties post birth. Literature with older mothers suggests that the experience for mothers differs based on these factors (Cronin et al., 1995; Davis, Edwards, Mohay, et al., 2003). Future research should examine if the distress and perceived challenges associated with having a preterm infant differs for young women depending on these factors.

\section{Conclusions}

The current findings suggest the birth of a preterm infant creates some additional challenges for young women during the acute stage of infant hospitalisation. However, the joy associated with becoming a mother is not diminished. This research suggests that an immediate, in the moment, frame of reference may be a protective factor for young women helping them maintain positive views of parenting. Further, our findings challenge assumptions about adolescent mothers and their needs by highlighting few differences in the experience of having a full-term or preterm infant over time. Broad group level categorizations based on age or infant birth status do not provide nuanced criteria for establishing which mothers need assistance managing the challenges of motherhood. Instead, systemic factors and internal resources of the individual need to be considered. 
The joys and challenges of motherhood

\section{References}

Abrahamse, A. F., Morrison, P. A., \& Waite, L. J. (1988). Beyond stereotypes: Who becomes a single teenage mother? Santa Monica, California: The RAND Corporation.

Arai, L. (2003). Low expectations, sexual attitudes and knowledge: explaining teenage pregnancy and fertility in English communities. Insights from qualitative research. The Sociological Review, 51(2), 199-218.

Arenson, J. D. (1994). Strengths and self-perceptions of parenting in adolescent mothers. Journal of Pediatric Nursing, 9(4), 251-258. doi: 0882-5963/94/0904-000753.00/0

Australian Bureau of Statistics. (2006). Socio-Economic Indexes for Areas (SEIFA)-technical paper (pp. 84). Canberra: Australia.

Barratt, M. S., Roach, M. A., Morgan, K. M., \& Colbert, K. K. (1996). Adjustment to motherhood by single adolescents. Family Relations, 45, 209-215.

Belsky, J. (1985). Exploring Individual Differences in Marital Change across the Transition to Parenthood: The Role of Violated Expectations. Journal of Marriage and the Family, 47(4), 1037-1044.

Boden, J. M., Fergusson, D. M., \& Horwood, L. J. (2008). Early motherhood and subsequent life outcomes. Journal of Child Psychology and Psychiatry, 49(2), 151-160. doi: 10.1111/j.1469-7610.2007.01830.x

Bunting, L., \& McAuley, C. (2004). Research review: Teenage pregnancy and parenthood: the role of fathers. Child and Family Social Work, 9, 295-303. doi: 10.1111/j.13652206.2004.00335.x

Cleveland, L. M. (2008). Parenting in the Neonatal Intensive Care Unit. Journal of Obstetric Gynecologic and Neonatal Nursing, 37(6), 666-691. doi: 10.1111/j.15526909.2008.00288.x 
The joys and challenges of motherhood

Crone, E. A. (2009). Executive functions in adolescence: Interferences from brain and behaviour. Developmental Science, 12(6), 825-830.

Cronin, C. M. G., Shapiro, C. R., Casiro, O. G., \& Cheang, M. S. (1995). The impact of very low-birthweight infants on the family is long lasting: A matched control study. Archive of Pediatric and Adolescent Medicine, 149, 151-158. doi: 10.1001/archpedi.1995.02170140033005

Davis, L., Edwards, H., \& Mohay, H. (2003). Mother-infant interaction in premature infants at three months after nursery discharge. International Journal Of Nursing Practice, 9(6), 374-381. doi: doi:10.1046/j.1440-172X.2003.00447.x

Davis, L., Edwards, H., Mohay, H., \& Wollin, J. (2003). The impact of very premature birth on the psychological health of mothers. Early Human Development, 73, 61-70. doi: 10.1016/S0378-3782(03)00073-2

Delmore-Ko, P. M., Pancer, S. M., Hunsberger, B., \& Pratt, M. (2000). Becoming a parent: The relation between prenatal expectations and postnatal experience. Journal of Family Psychology, 14(4), 625-640. doi: 10.1037//0893-3200.14.4.625

Farnell, L., Jones, L., Rowe, J., \& Sheeran, N. (2012). Effects of age and the preterm birth of an infant on adolescent mothers’ psychological adjustment. Child Health Care, 41(4), 302-321. doi: 10.1080/02739615.2012.721713

Fessler, K. B. (2008). Reclaiming a spoiled maternal identity: Young mothers' experiences and rejection of stigma. (Ph.D.), University of Michigan, Michigan.

Field, T., Widmayer, S. M., Stringer, S., \& Ignatoff, E. (1980). Teenage, lower-class, black mothers and their preterm infants: An intervention and developmental follow-up. Child Development, 51(2), 426-436. doi: 10.1111/j.1467-8624.1980.tb02563.x

Fischhoff, B. (2008). Assessing adolescent decision-making competence. Developmental Review, 28(1), 12-28. 
The joys and challenges of motherhood

Franck, L. S., Cox, S., Allen, A., \& Winter, I. (2005). Measuring neonatal intensive care unitrelated parental stress. Journal of Advanced Nursing, 49(6), 608-615. doi: 10.1111/j.1365-2648.2004.03336.x

Furstenberg, F. F. (1991). As the pendulum swings: Teenage childbearing and social concern. Family Relations, 40(2), 127-138.

Furstenberg, F. F., Brooks-Gunn, J., \& Chase-Lansdale, L. (1989). Teenaged pregnancy and childbearing. American Psychologist, 44(2), 313-320. doi: 10.1037/0003066X.44.2.313

Goldenberg, R. L. C. J. F. I. J. D. R. R. (2008). Epidemiology and causes of preterm birth. Lancet, 371(9606), 75-84.

Graham, H., \& McDermott, E. (2006). Qualitative research and the evidence base of policy: Insights from studies of teenage mothers in the UK. Journal of Social Policy, 35(01), 21-37. doi: doi:10.1017/S0047279405009360

Hanna, B. (2001). Negotiating motherhood: the struggles of teenage mothers. Journal of Advanced Nursing, 34(4), 456-464. doi: 10.1046/j.1365-2648.2001.01774.x

Holditch-Davis, D., \& Miles, M. (2000). Mothers' stories about their experiences in the neonatal intensive care unit. Neonatal Network, 19(1), 13-21.

Hunt-Morse, M. C. (2002). Adolescent mothers' psychosocial development: Implications for parenting. (Doctor of Philosophy), University of Oregon, Oregon.

Jones, L., Rowe, J., \& Sheeran, N. (2009). Teenage maternal adjustment during the transition from hospital to home with a pre-term or low birth weight infant: The role of community services (pp. 54). Brisbane: Griffith University and Department of Communities. 
The joys and challenges of motherhood

Jones, L., Rowe, J., \& Sheeran, N. (2010). Teenage maternal adjustment during the transition from hospital to home with a pre-term or low birth weight infant: One year post discharge. Brisbane: Griffith University and Department of Communities.

Kleiber, B. V., \& Dimidjian, S. (2014). Postpartum Depression Among Adolescent Mothers: A Comprehensive Review of Prevalence, Course, Correlates, Consequences, and Interventions. Clinical Psychology: Science and Practice, 21(1), 48-66. doi: 10.1111/cpsp.12055

Knaak, S. J. (2008). The process of postpartum adjustment. (Ph.D.), University of Alberta Canada.

Larkin, M., Eatough, V., \& Osborn, M. (2011). Interpretative phenomenological analysis and embodied, active, situated, cognition. Theory \& Psychology, 1-20. doi: $10.1177 / 0959354310377544$

Letourneau, N. L., Stewart, M., J., \& Barnfather, A. K. (2004). Adolescent mothers: Support needs, resources, and support-education interventions. Journal of Adolescent Health, 35, 509-525. doi: 10.1016/j.jadohealth.2004.01.007

Li, Z., Zeki, R., Hilder, L., \& Sullivan, E. A. (2011). Australia's mothers and babies Perinatal statistics series Number 28. Canberra: Australian Institute of Health and Welfare.

Li, Z., Zeki, R., Hilder, L., \& Sullivan, E. A. (2013). Australia's mothers and babies 2011. Perinatal statistics series no.28. Cat no. PER 59. Canberra: AIHW National Perinatal Epidemiology and Statistics Unit.

Linders, A., \& Bogard, C. (2014). Teenage pregnancy as a social problem: A comparison of Sweden and the United States. In A. L. Cherry \& M. E. Dillon (Eds.), International Handbook of Adolescent Pregnancy (pp. 147-157). New York: Springer Science + Business Media. 
The joys and challenges of motherhood

Meyer, E. C., Garcia Coll, C. T., Seifer, R., Ramos, A., Kilis, E., \& Oh, W. (1995). Psychological distress in mothers of preterm infants. Journal of Developmental and Behavioral Pediatrics, 16(6), 412-417. doi: 10.1097/00004703-199512000-00004

Miles, M. S., Holditch-Davis, D., Schwartz, T. A., \& Scher, M. (2007). Depressive symptoms in mothers of prematurely born infants. Journal of Developmental and Behavioural Pediatrics, 28, 36-44. doi: 10.1097/01.DBP.0000257517.52459.7a

Moffitt, T. E., \& the E-Risk Study Team. (2002). Teen-aged mothers in contemporary Britain. Journal of Child Psychology and Psychiatry, 43(6), 727-742. doi: $10.1111 / 1469-7610.00082$

Mollborn, S. (2007). Making the best of a bad situation: Material resources and teenage parenthood. Journal of Marriage and Family, 69(1), 92-107. doi: 10.1111/j.17413737.2006.00347.x

Montessoro, A. C., \& Blixen, C. E. (1996). Public policy and adolescent pregnancy: A reexamination of the issues. Nursing Outlook, 44(1), 31-36.

Paranjothy, S., Broughton, H., Adappa, R., \& Fone, D. (2009). Teenage pregnancy: who suffers? Archives of Disease in Childhood, 94(3), 239-245. doi: 10.1136/adc.2007.115915

Partington, S. N., Steber, D. L., Blair, K. A., \& Cisler, R. A. (2009). Second births to teenage mothers: Risk factors for low birth weight and preterm birth: Perspectives on Sexual and Reproductive Health.

Quinlivan, J. A., Petersen, R. W., \& Gurrin, L. C. (1999). Adolescent pregnancy: psychopathology missed. Australian and New Zealand Journal of Psychiatry, 33, 864-868. 
The joys and challenges of motherhood

Rai, R. K., Singh, P. K., Kumar, C., \& Parasuraman, S. (2013). Teenage childbearing: a growing public health concern in need of urgent policy and program action. Journal of Public Health, 21(4), 379-384. doi: http://dx.doi.org/10.1007/s10389-012-0551-6

Romagnoli, A., \& Wall, G. (2012). 'I know I'm a good mom': Young, low-income mothers' experiences with risk perception, intensive parenting ideology and parenting education programmes. Health, Risk \& Society, 14(3), 273-289. doi:

$10.1080 / 13698575.2012 .662634$

Roth, J. R., Hendrickson, J., \& Stowell, D. W. (1998). The risk of teen mothers having low birth weight babies: Implications of recent medical research for school health personnel. The Journal of School Health, 68(7), 271-275.

Rowley, A. A., Roesch, S. C., Jurica, B. K., \& Vaughn, A. A. (2005). Developing and validating a stress appraisal measure for minority adolescents. Journal of Adolescence, 28, 547-557. doi: 10.1016/j.adolescence.2004.10.010

Ruedinger, E., \& Cox, J. E. (2012). Adolescent childbearing: Consequences and interventions. Current Opinion in Pediatrics, 24(4), 446-452. doi: DOI:10.1097/MOP.0b013e3283557b89

Schellenbach, C. J., Whitman, T. L., \& Borowski, J. G. (1992). Towards an integrative model of adolescent parenting. Human Development, 35, 81-99.

Seamark, C. J., \& Lings, P. (2004). Positive experiences of teenage motherhood: a qualitative study. British Journal of General Practice, 54, 813-818.

Sheeran, N. (2012). Young women's experiences of being a mother to preterm infants: An interpretative phenomenological analysis (IPA) approach. (Doctor of Philosophy in Clinical Psychology), Brisbane, Australia.

Sheeran, N., Jones, L., \& Rowe, J. (2013). The relationship between maternal age, communication and supportive relationships in the neonatal nursery for mothers of 
The joys and challenges of motherhood

preterm infants. Journal of Neonatal Nursing, 19(6), 327-336. doi: http://dx.doi.org/10.1016/j.jnn.2013.01.006

Sheeran, N., Jones, L., Rowe, J., \& Zimmer-Gembeck, M. J. (2013). Young maternal age and preterm birth: Specific challenges during the transition to motherhood. In P. Barberis \& S. Petrakis (Eds.), Parenting: Challenges, Practices and Cultural Influences (pp. 134). New York: Nova Publishers.

Slattery, M. M., \& Morrison, J. J. (2002). Preterm delivery. Lancet, 360(9344), 1489.

Smith, J. A. (1995). Semi-structured interviewing and qualitative analysis. In J. A. Smith, R. Harrâe \& L. v. Langenhove (Eds.), Rethinking Methods in Psychology (pp. 9-26). London ; Thousand Oaks, Calif.: Sage Publications.

Smith, J. A. (2004). Reflecting on the development of interpretive phenomenological analysis and its contribution to qualitative research in psychology. Qualitative Research in Psychology, 1, 36-54. doi: 10.1191/1478088704qp004oa

Smith, J. A. (2011). Evaluating the contribution of interpretative phenomenological analysis. Health Psychology Review, 5(1), 9-27. doi: 10.1080/17437199.210.510659

Smith, J. A., Flowers, P., \& Larkin, M. (2009). Interpretative phenomenological analysis: Theory, method and research London: Sage.

Smith, J. A., \& Osborn, M. (2003). Interpretative phenomenological analysis. In J. A. Smith (Ed.), Qualitative Psychology : A Practical Guide to Research Methods (pp. 51-80). London: SAGE.

Smith, J. A., \& Osborn, M. (2008). Interpretative phenomenological analysis. In J. A. Smith (Ed.), Qualitative Psychology: A practical guide to research methods (2nd ed., pp. 53-80). London, England: Sage. 
The joys and challenges of motherhood

Smith, J. A., Osborn, M., \& Jarman, M. (1999). Doing interpretive phenomenological analysis. In M. Murray \& K. Chamberlain (Eds.), Qualitative health psychology: theories and methods. London: SAGE.

SmithBattle, L. (1995). Teenage mother's narratives of self: An examination of risking the future. Primary Care and Knowledge Development, 17(4), 22-36.

SmithBattle, L. (2012). Moving Policies Upstream to Mitigate the Social Determinants of Early Childbearing. Public Health Nursing, 29(5), 444-454. doi: 10.1111/j.15251446.2012.01017.x

SmithBattle, L., \& Leonard, W. (1998). Adolescent mothers four years later: Narratives of the self and visions for the future. Development and Aging, 20(3), 36-49.

Spear, H. J., \& Lock, S. (2003). Qualitative research on adolescent pregnancy: a descriptive review and analysis. Journal of Pediatric Nursing, 18(6), 397-408. doi: 10.1016/S0882-5963(03)00160-X

Thurman, S. K., \& Gonsalves, S. V. (1993). Adolescent mothers and their premature infants: Responding to double risk. Infants \& Young Children, 5(4), 44-51.

Whitfield, M. F. (2003). Psychosocial effects of intensive care on infants and families after discharge. Seminars in Neonatology, 8, 183-193. doi: 10.1016/S1084-2756(02)00218$\mathrm{X}$ 